\title{
Sclerostin/Receptor Related Protein 4 and Ginkgo Biloba Extract Alleviates $\beta$-Glycerophosphate-Induced Vascular Smooth Muscle Cell Calcification By Inhibiting Wnt/ $\beta$-Catenin Pathway
}

\author{
Jian Wang Xiaobo Qiu Tianhua Xu Zitong Sheng Li Yao \\ Department of Nephrology, The First Hospital of China Medical University, Shenyang, PR China
}

\author{
Keywords \\ Chronic kidney disease - Vascular calcification - Sclerostin . \\ Receptor-related protein 4 - Wnt/ $\beta$-catenin · Ginkgo biloba \\ extract
}

\begin{abstract}
Background: Abnormal mineral metabolism in patients with chronic kidney disease (CKD) may lead to vascular calcification, which is markedly associated with adverse events, including ischemic cardiac diseases and all-cause cardiovascular mortality. Thus, preventing and treating vascular calcification play an important role in improving the prognosis of CKD patients. Objectives: To investigate the potential functions of sclerostin and low-density lipoprotein receptor-related protein 4 (Lrp4) in alleviating the $\beta$-glycerophosphate ( $\beta$-GP)-induced vascular smooth muscle cell (VSMC) calcification, and the protective effect of Ginkgo biloba extract (GBE). Methods: VSMC were extracted from Sprague-Dawley rat aorta and cultured in medium. The VSMCs were divided into 3 groups: (1) Negative control group, (2) $\beta$-GP group, in which the VSMCs were treated with $\beta-G P$, and (3) GBE and $\beta$-GP group, where the VSMCs were treated with both $\beta$-GP and GBE. The calcium nodules within the cells were exam-
\end{abstract}

ined by using Alizarin red $\mathrm{S}$ staining. The mRNA expression levels of $\beta$-catenin and bone gamma-carboxyglutamic-acidcontaining proteins (BGP) were detected by real-time PCR. The protein levels of sclerostin and Lrp4 were determined by Western blot. Results: Alizarin red S staining showed that the VSMCs in $\beta$-GP group had a distinct orange-red precipitate when compared with VSMCs in the negative control group, while the orange-red precipitate of the GBE and $\beta$-GP group was significantly reduced compared to the $\beta$-GP group. Realtime PCR showed that the mRNA levels of $\beta$-catenin and BGP in VSMCs of $\beta$-GP group were significantly higher than those of the negative control group $(p<0.05)$; while they were significantly reduced in VSMCs of the GBE and $\beta$-GP group $(p<$ 0.05). Western blot results showed that the expression of sclerostin in the $\beta$-GP group was significantly higher than that in the control group $(p<0.05)$, whereas Lrp4 was significantly lower than in control group $(p<0.05)$. Sclerostin in GBE and $\beta$-GP group was significantly reduced $(p<0.05)$, but Lrp4 was significantly elevated when compared with that of the $\beta$-GP group $(p<0.05)$. Conclusion: $\beta$-GP induced VSMC calcification by activating the $\mathrm{Wnt} / \beta$-catenin signaling path-

J.W. and X.Q. contributed equally to this work.

\begin{tabular}{ll}
\hline KARGER & $\begin{array}{l}\text { Ko 2019 The Author(s) } \\
\text { Published by S. Karger AG, Basel Oper }\end{array}$ \\
E-Mail karger@karger.com & This article is licensed under the Creative Commons Attribution- \\
www.karger.com/bpu & $\begin{array}{l}\text { NonCommercial-NoDerivatives 4.0 International License (CC BY- } \\
\text { NC-ND) (http://www.karger.com/Services/OpenAccessLicense). } \\
\text { Usage and distribution for commercial purposes as well as any dis- } \\
\text { tribution of modified material requires written permission. }\end{array}$
\end{tabular}

Dr. Li Yao

Department of Nephrology, The First Hospital of China Medical University No. 155, Nanjing North Street, Heping District

Shenyang 110001 (PR China)

E-Mail liyao_cmu@163.com 
way. Sclerostin and Lrp4 were involved in $\beta$-GP-induced VSMC calcification and play an important role. GBE could alleviate VSMC calcification induced by $\beta$-GP through inhibiting the $\mathrm{Wnt} / \beta$-catenin signaling pathway.

(c) 2019 The Author(s)

Published by S. Karger AG, Basel

\section{Introduction}

Abnormal mineral metabolism in patients with chronic kidney disease (CKD) may lead to vascular calcification, and vascular calcification is significantly associated with adverse events such as ischemic cardiac events and all-cause cardiovascular mortality, thus preventing and treating vascular calcification play an important role in improving the prognosis of patients with CKD. Sclerostin inhibits the activity of osteoblasts by binding to the low density lipoprotein receptor-associated protein 5/6(Lrp5/6) and Frizzled complex receptors on the cell surface through inhibiting the $\mathrm{Wnt} / \beta$-catenin signaling pathway [1]. Low density lipoprotein receptor related protein 4 (Lrp4) is highly correlated with Lrp5/6 and may regulate bone balance by interacting with sclerostin [2]. Osteogenesis of vascular smooth muscle cell (VSMC) during vascular calcification has a similar process to osteogenic differentiation during bone formation, and sclerostin/Lrp4 may affect calcification by regulating osteogenic differentiation of VSMC. Studies have shown that Ginkgo biloba extract (GBE) can improve tissue oxygen supply and reduce vascular calcification in a dose-dependent manner [3], but the specific mechanism is not fully understood. In this study, VSMC calcification model was established through induction with $\beta$-glycerophosphate ( $\beta$-GP), and GBE was used for intervention. By examining the expression of $\beta$-catenin, bone gamma-carboxyglutamic-acid-containing proteins (BGP), sclerostin, and Lrp4, we discussed the mechanism of sclerostin/Lrp4 and GBE in regulating the process of $\beta$-GP-induced VSMC calcification.

\section{Materials and Methods}

Culturing and Identification of Primary VSMC

Aortic VSMC were extracted from Sprague Dawley (SD) rats, and cultured in HDMEM medium, containing 10\% fetal bovine serum (FBS Israel $\mathrm{BI}$ ) and $1 \%$ penicillin-streptomycin (Hyclone, USA). The cells were maintained in $37^{\circ} \mathrm{C}$ thermostatic incubator containing $5 \% \mathrm{CO}_{2}$. Cells were passaged at $70-80 \%$ confluence. Cells at passage 3 were used for cell morphology analysis and
a-SMA immunohistochemical staining. Immunohistochemical staining was performed using commercially available kit (Beyotime Biotechnology, China) according to the manufacturer's instructions. The VSMCs of passage 3 were fixed with $4 \%$ paraformaldehyde for $15 \mathrm{~min}$ at room temperature. Then, the cells were incubated successively with $5 \%$ BSA for 20 min at room temperature to block non-specific staining, with anti- $\alpha$-SMA (1:50) over night at $4^{\circ} \mathrm{C}$, and with horseradish peroxidase-conjugated secondary antibody for $20 \mathrm{~min}$ at $37^{\circ} \mathrm{C}$. Cells of the negative control group were incubated with PBS as vehicle. Afterwards, the cells were incubated with $\mathrm{SABC}$ for $20 \mathrm{~min}$ at $37^{\circ} \mathrm{C}$ and stained with $\mathrm{DAB}$. Experimental procedures were approved by the animal care and use committee of the institute.

\section{Cell Viability Examination}

Eight thousand VSMCs per $100 \mu \mathrm{L}$ complete medium were prepared in quintuplicate in the 96-well plate, and the cells were treated with different concentrations $(0,0.5,1.0,1.5$, and $2.0 \mathrm{mg} /$ $\mathrm{mL}$ ) of GBE (Dr. Weimar Shupei, Germany). After $72 \mathrm{~h}$, the original medium was discarded and $100 \mu \mathrm{L}$ fresh medium was added. According to the CCK 8 (Dojindo Japan) kit instructions: 10 ulcck was added -8 solution into each well and incubated for 3 $\mathrm{h}$ at $37^{\circ} \mathrm{C}$. The optical density (OD) value of each well was measured at $450 \mathrm{~nm}$ using an enzyme-linked immunosorbent assay reader. The relative cell viability was determined as $\mathrm{OD}_{\text {drug }} /$ $\mathrm{OD}_{0 \mathrm{mg} / \mathrm{L}}$.

\section{Experimental Grouping}

Cultured VSMCs were divided into 3 groups: Control group ( $1 \%$ fetal bovine serum + HDMEM); $\beta$-GP group ( $1 \%$ fetal bovine serum + HDMEM + $10 \mathrm{mmol} / \mathrm{L} \beta$ - GP $+50 \mathrm{ug} / \mathrm{mL}$ ascorbic acid); GBE and $\beta$-GP group $(0.5 \mathrm{mg} / \mathrm{mL} \mathrm{GBE}+1 \%$ fetal bovine serum + HDMEM + $10 \mathrm{mmol} / \mathrm{L} \beta-\mathrm{GP}+50 \mu \mathrm{g} / \mathrm{mL}$ ascorbic acid). Cells were cultured for 14 days and the medium was replaced every 2-3 days.

Alizarin red S staining for calcification of VSMC in each group: After treatment for 14 days, the VSMCs were fixed in $95 \%$ ethanol for $1 \mathrm{~h}$ at room temperature. The cells were then stained with $1 \%$ Alizarin red solution (Shanghai Jiemei gene) for $30 \mathrm{~min}$ at $37^{\circ} \mathrm{CC}$. Next, the cells were washed with PBS for 3 times to remove nonspecific staining. The mineralized nodules were seen orange-red under the microscope.

Real-Time PCR was Used to Detect the Expression of BGP and $\beta$-Catenin mRNAs in each Group

The total RNA of each group was extracted using Trizol (Takara), total RNA concentration and purity were measured, and reverse transcription was performed according to the instructions of the Reverse Transcription Kit (Takara). Real-time PCR was performed by using SYBR-based kit (Takara SYBR Premix Ex Taq ${ }^{\mathrm{T}-}$ $\left.{ }^{M} \mathrm{II}\right)$. The specific primers (Sangon biological) used were as follows: $\beta$-catenin (forward: $5^{\prime}$-C T T A C G G C A A T C A G G A AA G C- $3^{\prime}$, reverse: $5^{\prime}$-T C A G C A C T C T G C T T G T G G T C- $3^{\prime}$ ); BGP (forward: 5'-C C T G A C T G C A T T C T G C C T C T-3', reverse: $5^{\prime}$-A G G T A G C G C C G G A G T C T A T T- $3^{\prime}$ ); $\beta$-actin (forward: 5' -T G T C A C C A A C T G GG A C G A T A-3', reverse: $5^{\prime}$-G G GG T GT T G A A G G T C T C A A A- $3^{\prime}$ ). The analysis was carried out by using a real-time PCR instrument (LightCycler 480II). The reaction conditions were $95^{\circ} \mathrm{C}$ for $10 \mathrm{~min} ; 95^{\circ} \mathrm{C}$ for 10 s, $60^{\circ} \mathrm{C}$ for $20 \mathrm{~s}, 72^{\circ} \mathrm{C}$ for $30 \mathrm{~s}, 40$ cycles; $4^{\circ} \mathrm{C}$ for $5 \mathrm{~min}$. $\beta$-actin
18

Blood Purif 2019;47(suppl 1):17-23 DOI: $10.1159 / 000496219$
Wang/Qiu/Xu/Sheng/Yao 
was set as internal reference. The relative expression levels of the target genes were expressed as $2^{-\Delta \Delta \mathrm{Ct}}$.

Western Blot was used to detect the expression of sclerostin and Lrp4 proteins in each group. The total protein of each group was extracted using 1\% PMSF lysate (Beyotime Biotechnology, China). The protein extracts were then quantified with the BCA method. Equal amounts of protein were subjected to SDS-PAGE, followed by transfer onto PVDF membranes. The membranes with proteins were incubated successively with $5 \%$ non-fat milk for $1 \mathrm{~h}$ at room temperature, with appropriate primary antibodies overnight at $4{ }^{\circ} \mathrm{C}$, and with horseradish peroxidase-conjugated secondary antibody (1:2,000, Proteintech Group, Lnc, China) for $1 \mathrm{~h}$ at room temperature. The following primary antibodies were used: anti-Lrp4 (1:500, Boaosen), anti-Sclerostin (1:500, Boaosen), anti- $\beta$-actin (1:1,000, Boaosen). The membranes were then developed by ECL detection system. All bands were analyzed using Image J software (NIH, USA). Normalization was performed with $\beta$-actin.

\section{Statistical Analysis}

Each of the experiments was performed 3 times. Statistical analysis was performed on the obtained data using SPSS 13.0 software. Measurement data that conformed to a normal distribution were described by mean $\pm \mathrm{SD}$, and multi-sample comparisons were analyzed by 1-way ANOVA. The LSD test was used to compare the variance between 2 groups. Differences were considered statistically significant at $p<0.05$.

\section{Results}

\section{Identification of VSMC}

The morphology of the cells was observed under a microscope, and the cells were observed to have a "peak-tovalley"-like shape as shown in Figure 1. "Peak-to-valley"like shape is a characteristic of VSMC growth.

Next, the primordial VSMC was identified by using the a-SMA monoclonal antibody immunoassay, as shown in Figure 2. The positive result was shown as brown cytoplasm, while the negative control was purple.

\section{The Effect of GBE on VSMC Viability}

To investigate the potential cytotoxic effect of GBE on VSMCs, we first treated the VSMCs with GBE at a series of concentrations for $72 \mathrm{~h}$, and evaluated the relative cell viability by using CCK-8. As shown in Figure 3, the relative VSMC viability was negatively associated with the concentration of GBE, where only the viability with 0.5 $\mathrm{mg} / \mathrm{mL}$ GBE was not significantly hampered.

\section{GBE Alleviates $\beta$-GP-Induced VSMC Calcification}

The $\beta$-GP group had obvious calcium deposition, and the GBE and $\beta$-GP groups had significantly less calcium deposition than the $\beta$-GP group as shown in Figure 4.

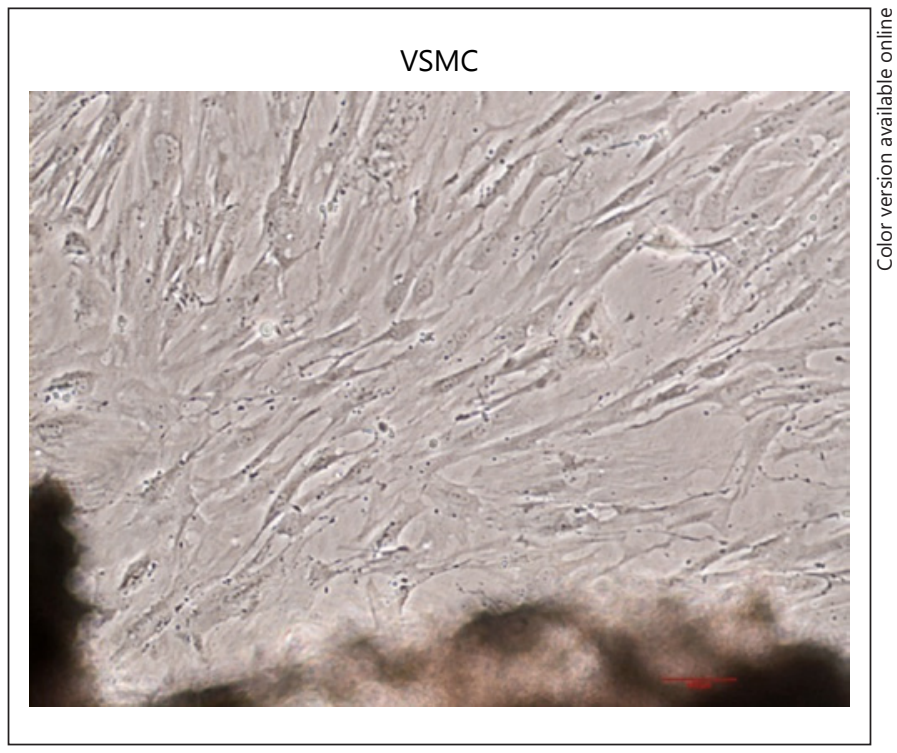

Fig. 1. Culturing of Primary SD rat VSMC $(\times 100)$. Primary cells exhibit typical "peak-to-valley"-like growth. Representative images are shown. VSMC, vascular smooth muscle cells.

Alizarin red S staining revealed that $\beta$-GP enhanced the calcium deposition in VSMCs when compared with that in the control group and GBE can reduce calcium deposition compared with that in the $\beta$-GP group.

\section{Expression of $\beta$-catenin and BGP $m R N A$ in Each Group}

The $\beta$-catenin mRNA expression of each group is shown in Figure 5: The expression of $\beta$-catenin in the $\beta$-GP group was higher than that in the other groups. The expression of $\beta$-catenin in GBE and $\beta$-GP group was lower than that in the $\beta$-GP group. The BGP mRAN expression of each group is shown in Figure 6: The BGP expression in $\beta$-GP group was higher than that in the other groups; the expression of BGP in the GBE and $\beta$-GP group was lower than that in the $\beta$-GP group.

\section{Sclerostin and Lrp4 Protein Expression in Each Group}

Sclerostinprotein expression in each group is shown in Figure 7: The expression of sclerostin in $\beta$-GP group was higher than that in the other groups. The expression of sclerostin in the GBE and $\beta$-GP group was lower than that in the $\beta$-GP group. The expression of Lrp4 protein in each group is shown in Figure 8: The expression of Lrp4 in the $\beta$-GP group was lower than that in the other groups; the expression of Lrp4 in GBE and $\beta$-GP group was higher than that in the $\beta$-GP group. 
Fig. 2. Immunohistochemical staining of a-SMA in VSMCs. The brown color within cytoplasm indicates positive staining. Representative images are shown. $\times 400$.

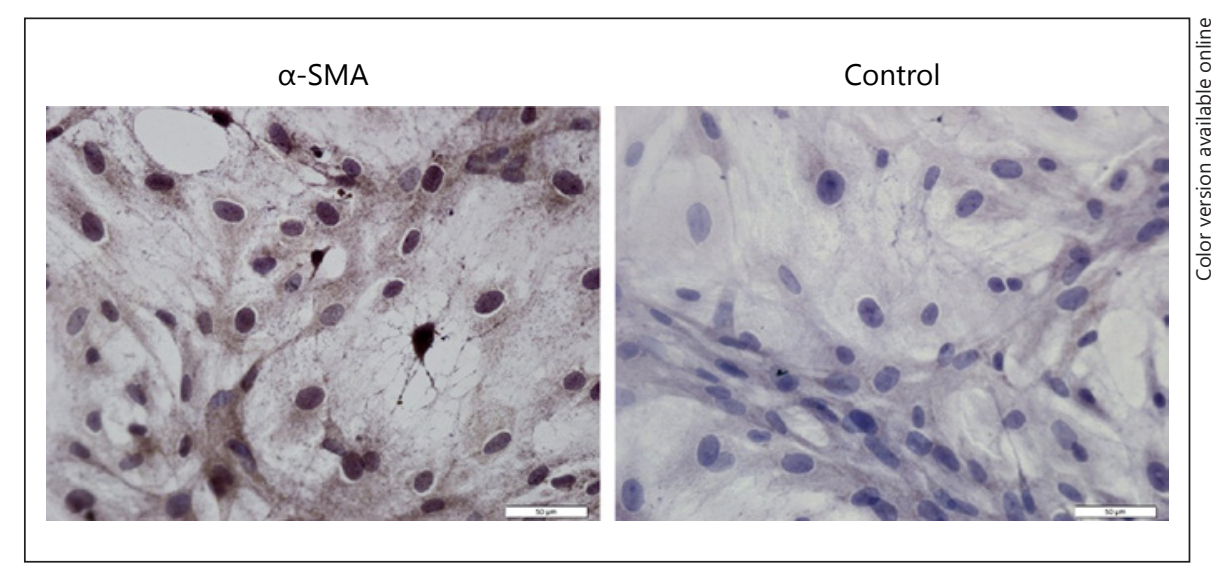

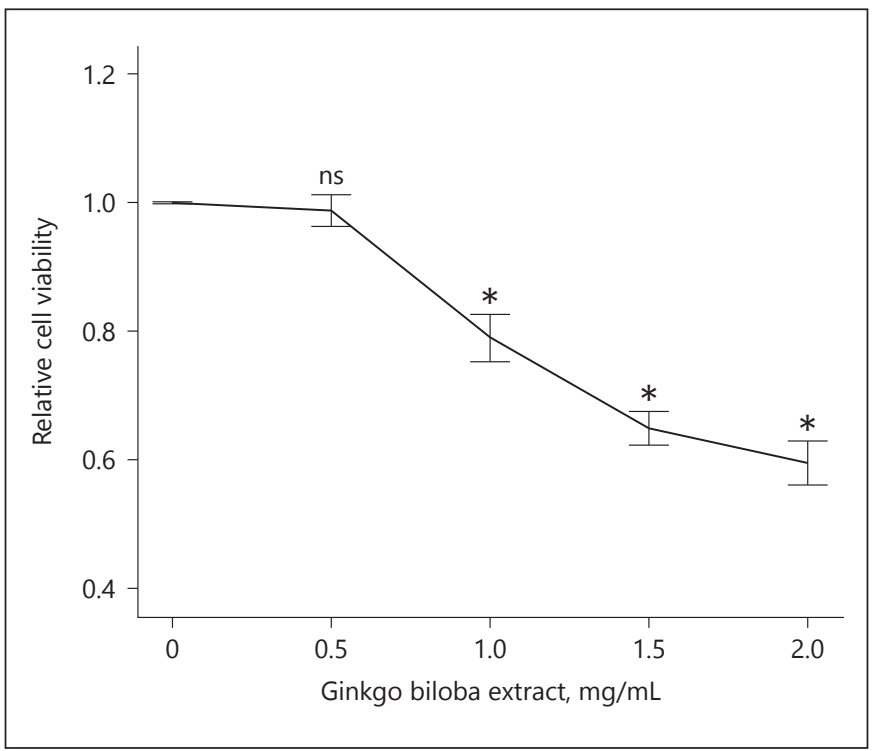

Fig. 3. The effect of GBE on VSMC viability: VSMCs were treated with GBE at different concentrations $(0-2.0 \mathrm{mg} / \mathrm{mL})$ for $72 \mathrm{~h}$, and relative cell viability was determined using CCK-8 as relative absorbance versus $0 \mathrm{mg} / \mathrm{L}(n=3)$. ns: no significant difference; ${ }^{*} p<$ 0.05 .

\section{Discussion}

Vascular calcification is a process of vascular wall thickening and loss of elastic fibers in the arterial wall, which occurs mainly in the intima and media of the vessels. Intimal calcification leads to atherosclerotic plaques [4], and medial calcification can lead to both arteriosclerosis and atherosclerosis. Patients with CKD have a higher proportion of tunica media calcification [5]. Studies have shown that high phosphorus can promote VSMC to become osteochondral phenotype $[6,7]$. In this experi- ment, we induced VSMC calcification by $\beta-G P$, which is similar to the disorder of calcium and phosphorus metabolism in patients with CKD. Alizarin red staining showed that the $\beta$-GP group had obvious orange-red precipitation when compared with other groups.

BGP. BGP is a sensitive marker of bone formation and also an important indicator of bone metabolism. In this experiment, the expression of BGP mRNA in $\beta$-GP group was higher than that of other groups, suggesting that VSMC was changed into the osteogenicpheno type.

In 1982, NUSSE and VARMUS discovered the Wnt signaling pathway when they studied the mouse mammary tumor virus. Subsequently, it was found that $\beta$-catenin was the most critical regulatory factor and the $\mathrm{Wnt} / \beta$-catenin pathway was proposed. $\mathrm{Wnt} / \beta$-catenin is an important signaling pathway regulating osseointegration [8-10]. It has significant effects on bone formation and bone disease [11]. In this experiment, the $\beta$-catenin mRNA expression of $\beta$-GP group was higher than that in other groups, suggesting that $\mathrm{Wnt} / \beta$-catenin signaling pathway is involved in $\beta$-GP -induced VSMC calcification.

Sclerostin is a product of the SOST gene in bone cells and articular chondrocytes $[12,13]$. It is a monomeric glycoprotein containing a cysteine knot-like domain, similar to the bone shape protein antagonists $[14,15]$. Sclerostin can inhibit the Wnt/ $\beta$-catenin signaling pathway through combining to the LRP5/6 and Frizzled complex receptors on the surface of osteoblasts [16], and then inhibit osteoblast differentiation, proliferation, and activity, resulting in reduced bone formation [17]. Since osteogenic differentiation of VSMC during vascular calcification has a similar process of bone formation, sclerostin may affect vascular calcification by regulating osteogenic differentiation of VSMC. 


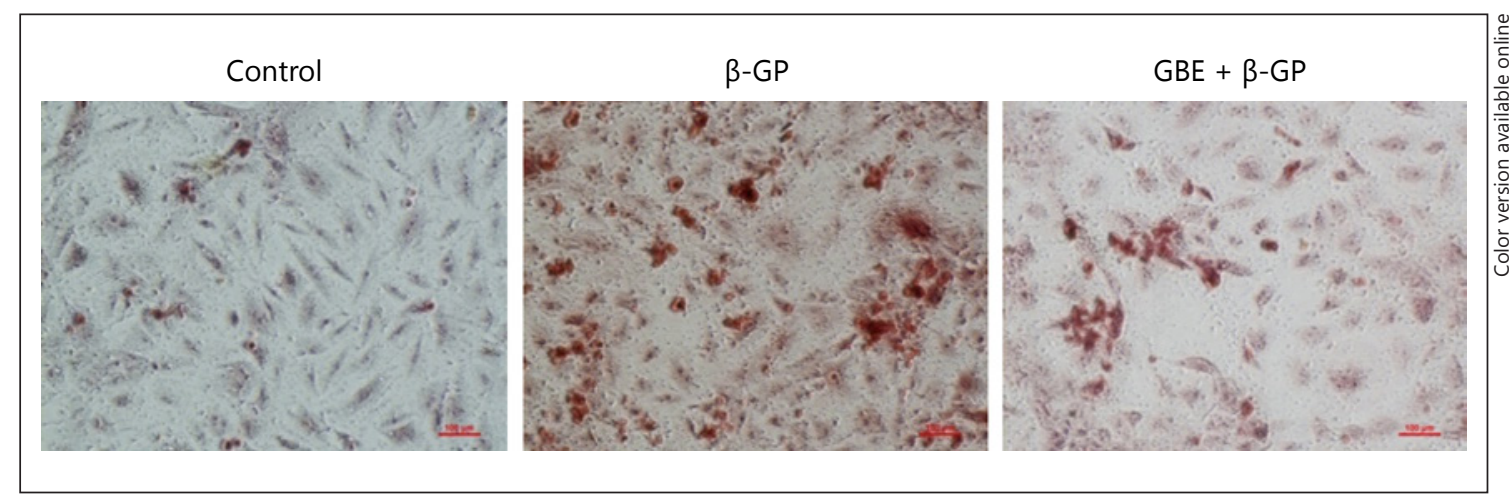

Fig. 4. The effects of Ginkgo biloba extract (GBE), $\beta$-GP, on VSMC calcification. VSMCs were treated with $\beta$-GP $(10 \mathrm{mmol} / \mathrm{L}+50 \mathrm{ug} /$ $\mathrm{mL}$ ascorbic acid) to induce calcification. VSMCs were treated with $\beta$-GP $(10 \mathrm{mmol} / \mathrm{L}+50 \mathrm{ug} / \mathrm{mL}$ ascorbic acid $)$ and GBE $(0.5$ $\mathrm{mg} / \mathrm{mL}$ ) to examine the effect of GBE on calcification. After 14

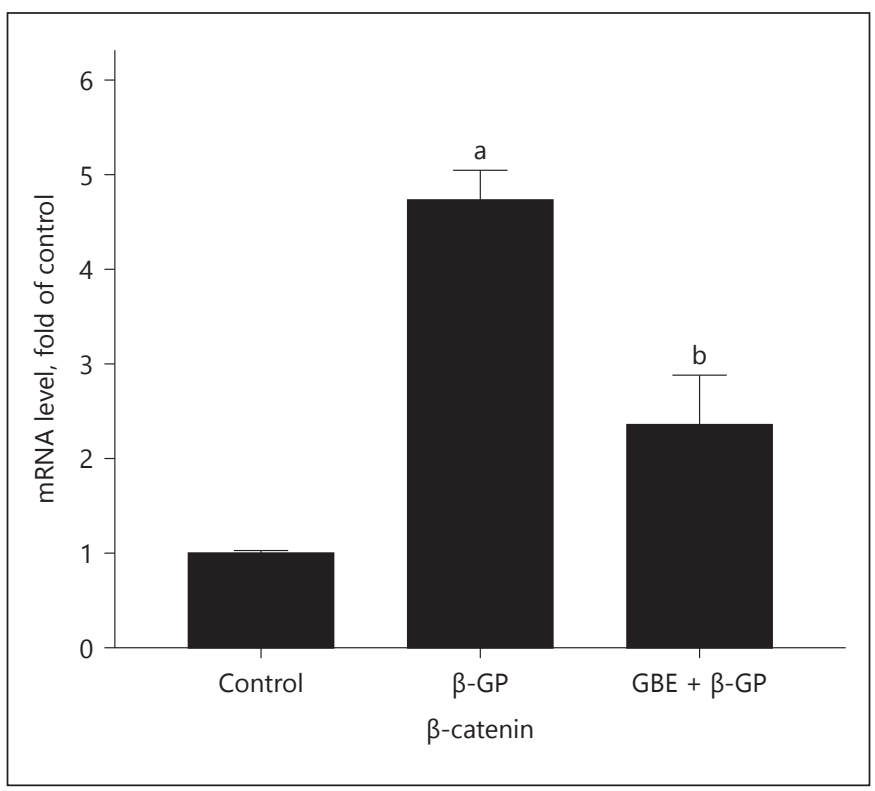

Fig. 5. mRNA expression of $\beta$-catenin: $\mathrm{Ctrl}$ (control group); $\beta$-GP ( $\beta$-GP group); GBE $+\beta-\mathrm{GP}$ (GBE and $\beta$-GP group). Results are presented as $\beta$-GP group compared with the control group, ${ }^{a} p<$ 0.05 ; GBE and $\beta$-GP compared with the $\beta$-GP group, ${ }^{b} p<0.05$. Representative images are shown $(n=3)$.

A recent study found that Lrp4 may regulate bone balance by interacting with sclerostin, but how it regulates bone balance remains unclear [18]. Lrp4 is highly dependent on Lrp5/6 as a receptor for the neuroproteoglycansAgrin [19]. Chang et al. [20] found that Lrp4 can promote sclerostin antagonistic WNT pathway days, the cells were subjected to Alizarin red S staining to examine the mineralized nodules under microscope; Representative images are shown $(n=3)$. $\beta$-GP, $\beta$-glycerophosphate; GBE, Ginkgo biloba extract.

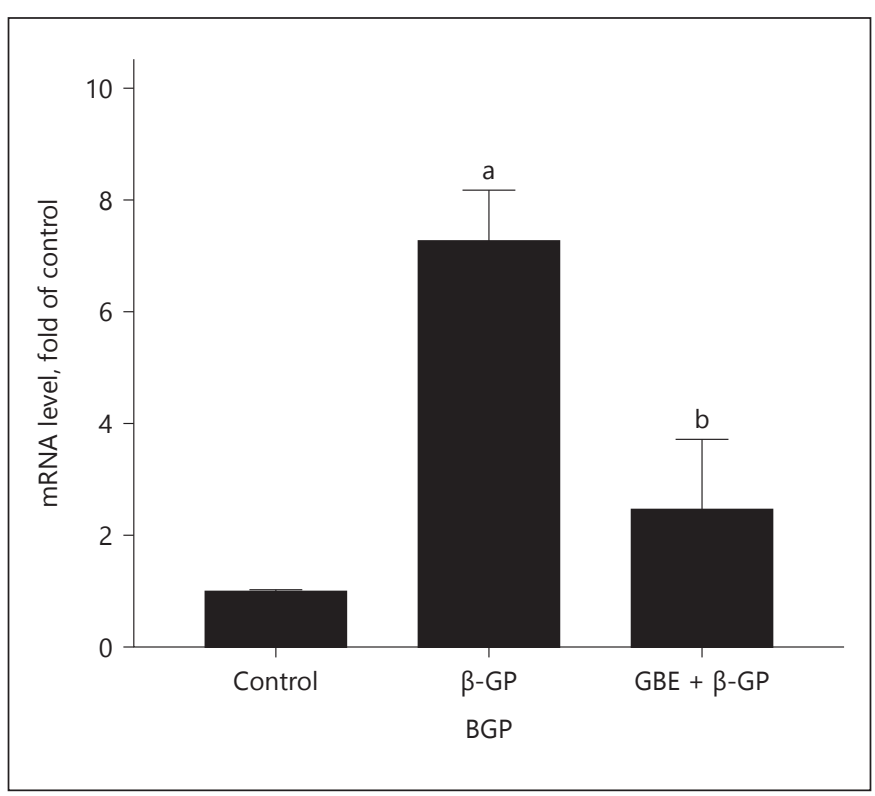

Fig. 6. mRNA expression of BGP: Ctrl (control group); $\beta$-GP ( $\beta$ GP group); GBE $+\beta-\mathrm{GP}$ (GBE and $\beta-\mathrm{GP}$ group). Results are presented as $\beta$-GP group compared with the control group, ${ }^{a} p<0.05$; GBE and $\beta$-GP compared with the $\beta$-GP group, ${ }^{\mathrm{b}} p<0.05$. Representative images are shown $(n=3)$. BGP, bone gamma-carboxyglutamic-acid-containing proteins.

and when the LRP4 gene is defective, the high bone mass is similar to that of patients with sclerostin. Leupin et al. [18] reported that biochemical tests of recombinant proteins confirmed that sclerostin interacts directly with Lrp4. These evidences suggest that Lrp4 may act as a receptor for sclerostin, inhibiting Wnt/ $\beta$ - 


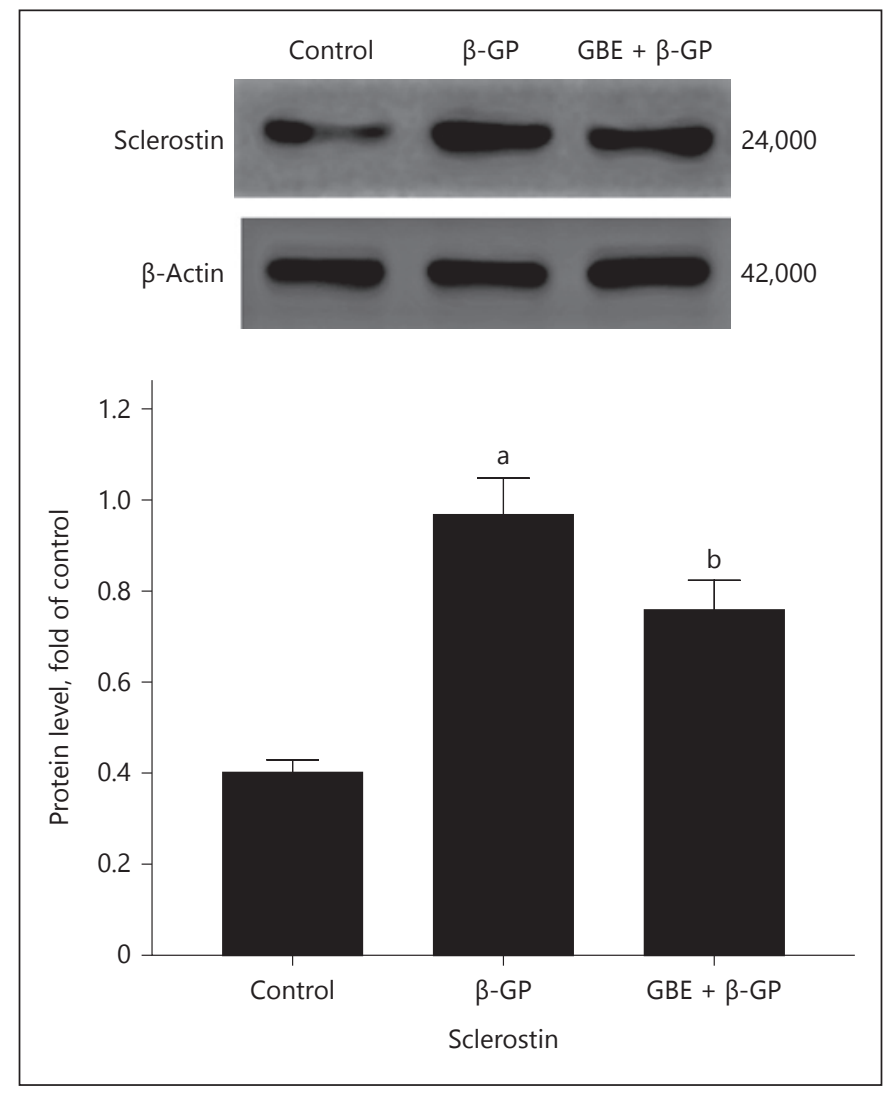

Fig. 7. Sclerostin protein expression: Ctrl (control group); $\beta$-GP ( $\beta$-GP group); GBE $+\beta$-GP (GBE and $\beta$-GP group). Results are presented as $\beta$-GP group compared with the control group, ${ }^{a} p<$ 0.05 ; GBE and $\beta$-GP compared with the $\beta$-GP group, ${ }^{\mathrm{b}} p<0.05$. Representativeimages are shown $(n=3) . \beta$-GP, $\beta$-glycerophosphate; GBE, Ginkgo biloba extract.

catenin signaling and bone formation. Clinical studies have found Lrp4 gene mutations in high bone mass diseases such as Von Buchem diseases and osteopetrosis. In addition, Lrp4 function loss increased the level of osteosclerotic protein in serum, but the inhibiting effect of bone sclerosis protein on $\mathrm{Wnt} / \beta$-catenin signal pathway was eliminated. Whether Lrp4 is involved in the regulation of vascular calcification has not been studied. In this study, the expression of sclerostin was significantly higher in $\beta$-GP group than that in other groups. However, the expression of Lrp4 was significantly reduced, so that the increased sclerostin could not fully exert the effect of inhibiting the $\mathrm{Wnt} / \beta$-catenin signal pathway and thereby alleviating VSMC calcification. It is suggested that Lrp4 plays a facilitating role in the inhibition of VSMC calcification caused by sclerostin through the $\mathrm{Wnt} / \beta$-catenin signaling pathway.

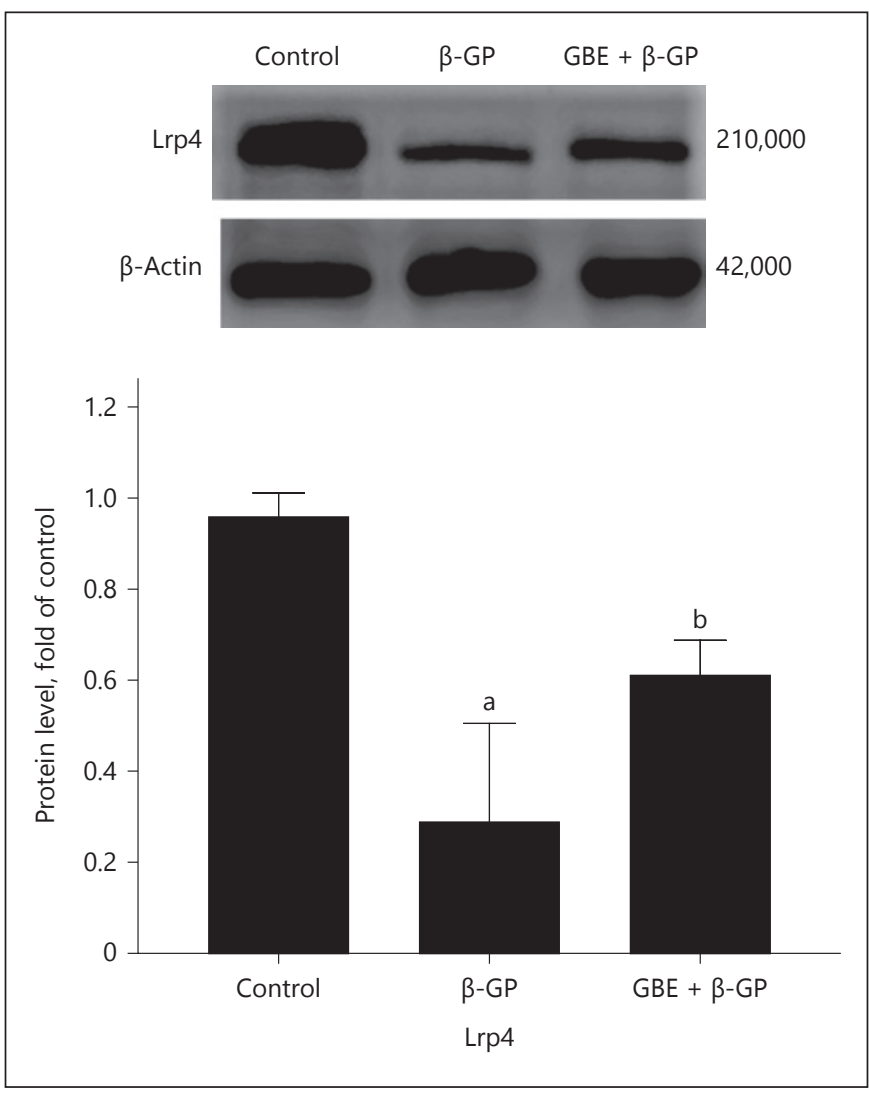

Fig. 8. Lrp4 protein expression: $\mathrm{Ctrl}$ (control group); $\beta$-GP (group); $\mathrm{GBE}+\beta-\mathrm{GP}$ (GBE and $\beta-\mathrm{GP}$ group). Results are presented as $\beta-\mathrm{GP}$ group compared with the control group, ${ }^{\mathrm{a}} p<0.05$; GBE and $\beta$-GP compared with the $\beta$-GP group, ${ }^{\mathrm{b}} p<0.05$. Representative images are shown $(n=3)$. $\beta$-GP, $\beta$-glycerophosphate; GBE, Ginkgo biloba extract; Lrp4, receptor-related protein 4 .

Studies have shown that GBE can improve tissue oxygen supply, reduce oxygen extraction and consumption, and maintain a balance between oxygen supply and consumption. It will reduce mitochondrial ROS production, thereby reducing vascular calcification [21]. However, whether GBE affects the $\mathrm{Wnt} / \beta$-catenin signaling pathway during $\beta$-GP-induced VSMC calcification has not been studied. In this experiment, we used GBE to intervene $\beta$-GP -induced VSMC calcification. The results of alizarin red staining showed that VSMC calcification in GBE and $\beta$-GP group was significantly reduced compared with that of the $\beta$-GP group; the mRNA expression of BGP and $\beta$-catenin in GBE and $\beta$-GP group was significantly lower than that in the $\beta$-GP group. The above results suggest that GBE can alleviate VSMC calcification and play a protective role in the process of VSMC calcification induced by $\beta$-GP, the mechanism of which is probably that GBE can inhibit the Wnt/ $\beta$-catenin signaling pathway. 
Hyperphosphatemia is the main cause of vascular calcification in patients with $\mathrm{CKD}$, and vascular calcification is an independent risk factor for cardiovascular and cerebrovascular diseases. This study demonstrates that high phosphorus can induce VSMC calcification by activating the $\mathrm{Wnt} / \beta$-catenin signaling pathway. Sclerostin/Lrp4 is involved in high phosphorus-induced VSMC calcification and plays an important role. GBE can alleviate high phosphorus-induced VSMC calcification by inhibiting Wnt/ $\beta$ catenin signaling pathway. Further studies are needed to prove that GBE can relieve vascular calcification in patients with $\mathrm{CKD}$ and open up new ideas for clinical treatment.

\section{Acknowledgment}

This work was supported by the National Natural Science Foundation of China (grant 81770766) and Provincial Natural Science Foundation of Liaoning (grant 20170540999).

\section{Ethics Statement}

Animal experiments conformed to the animal care and use committee guidelines of the China Medical University.

\section{Disclosure Statement}

The authors declare that they have no conflicts of interest.

\section{Funding Sources}

This work was supported by the National Natural Science Foundation of China (grant 81770766) and Provincial Natural Science Foundation of Liaoning (grant 20170540999).

\section{Author Contributions}

As X.Q. contributed greatly to the experiment and to the writing of this article; she is the co-first author.

\section{References}

1 Li X, Zhang Y, Kang H, et al: Sclerostin binds to LRP5/6 and antagonizes canonical Wnt signaling. J Biol Chem 2005;280:1988319887.

2 Xiong L, Jung JU, Wu H, et al: Lrp4 in osteoblasts suppresses bone formation and promotes osteoclastogenesis and bone resorption. Proc Natl Acad Sci 2015;112:3487-3492.

$3 \mathrm{Xu} \mathrm{L}, \mathrm{Hu}$ Z, Shen J, et al: Effects of Ginkgo biloba extract on cerebral oxygen and glucose metabolism in elderly patients with pre-existing cerebral ischemia. Complement Ther Med 2015;23:220-205.

4 Hunt JL, Fairman R, Mitchell ME, et al: Bone formation in carotid plaques: a clinicopathological study. Stroke 2002;33:1214-1219.

5 Giachelli CM: The emerging role of phosphate in vascular calcification. Kidney Int 2009;75:890-897.

6 La MarcaA, Sunkara SK: Individualization of controlled ovarian stimulation in IVF using ovarian reserve markers: from theory to practice. Hum Reprod Update 2014;20:124-140.

7 Giachelli CM, Speer MY, Li X, et al: Regulation of vascular calcification: roles of phosphate and osteopontin. Circ Res 2005;96:717722.

8 Wang Y, Li YP, Paulson C, et al: Wnt and the Wnt signaling pathway in bone development and disease. Front Biosci (Landmark Ed) 2013;19:379-407.

9 Baron R, Kneissel M: WNT signaling in bone homeostasis and disease: from human mutations to treatments. Nat Med 2013;19:179_ 192.

10 Day TF, Guo X, Garrett-Beal L, et al: Wnt/ beta-catenin signaling in mesenchymal progenitors controls osteoblast and chondrocyte differentiation during vertebrate skeletogenesis. Dev cell 2005;8:739-750.

11 Wang Y, Li YP, Paulson C, et al: Wnt and the Wnt signaling pathway in bone development and disease. Frontiers in Bioscience Landmark Ed 2013;19:379-407.

12 Porsová-Dutoit I: [Place of inhibin B investigation in clinical andrological praxis]. Vnitr Lék 2008;54:1059-1062.

13 Haouzi D, De VJ, Loup V, et al: [Oocyte and embryo quality: do the apoptotic markers have a place in the preimplantation genetic diagnostic?]. Gynécol Obstét Fertil 2008;36: 730-742.

14 Balemans W, Ebeling M, Patel N, et al: Increased bone density in sclerosteosis is due to the deficiency of a novel secreted protein (SOST). Hum Mol Genet 2001;10:537-543.

15 Brunkow ME, Gardner JC, Ness JV, et al: Bone dysplasia sclerosteosis results from loss of the SOST gene product, a novel cystine knot-containing protein. Am J Hum Genet 2001;64:577-589.

16 Li X, Zhang Y, Kang H, et al: Sclerostin binds to LRP5/6 and antagonizes canonical Wnt signaling. J Biol Chem 2005;280:1988319887.

17 Lewiecki EM: Role of sclerostin in bone and cartilage and its potential as a therapeutic target in bone diseases. Ther Adv Musculoskelet Dis 2014;6:48-57.

18 Leupin O, Piters E, Halleux C, et al: Bone overgrowth-associated mutations in the LRP4 gene impair sclerostin facilitator function. J Biol Chem 2011;286:19489-19500.

19 Barik A, Lu Y, Sathyamurthy A, et al: LRP4 is critical for neuromuscular junction maintenance. J Neurosci 2014;34:13892-13905.

20 Chang MK, Kramer I, Huber T, et al: Disruption of Lrp4 function by genetic deletion or pharmacological blockade increases bone mass and serum sclerostin levels. Proc Natl Acad Sci USA 2014;111:E5187E5195.

$21 \mathrm{Xu} \mathrm{L}, \mathrm{Hu} \mathrm{Z}$, Shen J, et al: Effects of Ginkgo biloba extract on cerebral oxygen and glucose metabolism in elderly patients with pre-existing cerebral ischemia. Complement Ther Med 2015;23:220-225. 